\section{Carcinoma epidermoide primario del estómago. Reporte de tres casos}

\author{
GERMÁN CALDERILLO-RUIZ ${ }^{1}$, ROBERTO HERRERA-GOEPFERT², \\ MARYTERE HERRERA MARTÍNEZ1 ${ }^{1}$, ELIZABETH TREJO DURÁN ${ }^{4}$, \\ BERENICE CARBAJAL-LÓPEZ ${ }^{1}$
}

\section{Primary squamous cell carcinoma of the stomach. Report of three cases}

Gastric squamous cell carcinoma (SCC) is a rare type of cancer. We report three patients with the tumor. A 65 years old male presenting with weight los and heartburn. An upper gastrointestinal endoscopy revealed an ulcerated tumor whose biopsy disclosed a gastric epidermoid carcinoma. The patient was operated and chemotherapy was attempted, but he died five months later. A 39 years old male with an antral tumor corresponding to an epidermoid carcinoma. He was operated and received chemotherapy and radiotherapy and died one year later. A 79 years old female with a distal antral tumor corresponding to a undifferentiated epidermoid carcinoma. She received palliative therapy and died two months later.

(Rev Med Chile 2018; 146: 1205-1209)

Key words: Carcinoma, Squamous Cell; Case Reports; Stomach.
'Departamento de Oncología

Médica, Instituto Nacional de

Cancerología, México

¿2ubdirección de Patología y

${ }^{3}$ Departamento de Radioterapia,

Instituto Nacional de

Cancerología, México.

Trabajo no recibió

financiamiento.

Los autores declaran no tener

conflictos de interés.

Recibido el 18 de enero de 2018, aceptado el 21 de septiembre de 2018.

Correspondencia a:

Dr. Germán Calderillo Ruiz

Unidad Funcional de Oncología

Gastrointestinal.

Instituto Nacional de

Cancerología. México.

calderillo06@yahoo.com.mx
E 1 carcinoma epidermoide, puro o combinado primario del estómago (CEG) es raro. El primer caso de CEG fue informado por Rolleston y Trevor (1905) ${ }^{1-3}$. Alrededor de $1 \%$ de los adenocarcinomas gástricos tienen componente epidermoide 4 , pero la incidencia de CEG es de 0,04-0,4\% del total de los carcinomas gástricos ${ }^{5}$.

Se han descrito menos de 100 casos de $\mathrm{CEG}^{6,7}$. Por tal motivo, presentamos tres casos de carcinoma epidermoide primario del estómago, confirmados histológicamente que acudieron a consulta del Instituto Nacional de Cancerología (INCan).

\section{Caso 1}

Hombre de 65 años, con antecedentes familiares de padre muerto por cáncer gástrico y personales de alcoholismo semanal durante 30 años, diabetes mellitus de 24 años de evolución, tratado con glibenclamida.

Consulto por historia clínica de fatiga de 6 meses de evolución, pérdida de peso (12 kg), pi- rosis y reflujo gastroesofágico. En el último mes se agregaron al cuadro clínico, anorexia, disnea de grandes esfuerzos, vómito matutino y melena. A su ingreso a nuestra institucion, mostraba palidez moderada de tegumentos, tensión arterial (TA) de $90 / 70 \mathrm{mmHg}$, frecuencia cardiaca de $108 \mathrm{x}^{\prime}$, frecuencia respiratoria de $24 x^{\prime} e$ índice de Karnofsky (IK) de $80 \%$; en la exploración física presentó dolor abdominal en epigastrio, sin tumor palpable ni ascitis. Los estudios de laboratorio mostraron: leucocitos $19.300 \mathrm{cel} / \mathrm{mm}^{3}$, neutrófilos $16.200 \mathrm{cel} /$ $\mathrm{mm}^{3}$, hemoglobina $(\mathrm{Hb}) 8,2 \mathrm{~g} / \mathrm{dl}$, hematocrito (Hto) $24,4 \%$, plaquetas $701.000 \mathrm{cel} / \mathrm{mm}^{3}$, glucosa $331 \mathrm{mg} / \mathrm{dl}$ y albúmina 2,16 g/l. En la tomografía axial computada (TAC) se observó engrosamiento difuso de pared gástrica y la endoscopia mostró un tumor de $5 \mathrm{~cm}$ en el cuerpo gástrico, ulcerado y excavado, con bordes elevados e infiltrantes. Se practicó biopsia con informe histopatológico de carcinoma epidermoide del estómago. El paciente recibió tratamiento sintomático y transfusión sanguínea, con mejoría de condiciones generales. 
Se realizó exploración quirúrgica con hallazgo de tumor en el cuerpo gástrico, que infiltraba la cola del páncreas y el colon transverso. Se le efectuó gastrectomía subtotal con pancreatectomía distal y resección segmentaria de colon transverso y mesocolon.

El estudio patológico mostró una neoplasia en la curvatura mayor del estómago de $8,5 \times 6,3 \mathrm{~cm}$, ulcerada con infiltración gástrica hasta tejido adiposo y la pared de intestino grueso. Con diagnóstico de carcinoma epidermoide moderadamente diferenciado (Figuras 1 y 2 ), con metástasis en $8 / 13$ ganglios linfáticos perigástricos y en dos conglomerados ganglionares regionales. La etapificación posquirúrgica fue $\mathrm{pT} 4, \mathrm{pN} 2$, pMX (etapa IV).

Dos meses después de la cirugía, se inició tratamiento complementario con quimioterapia a base de cisplatino $\left(75 \mathrm{mg} / \mathrm{m}^{2}\right)$ día 1 , y 5-Fluorouracilo $\left(750 \mathrm{mg} / \mathrm{m}^{2}\right)$ días $1-4$, cada 3 semanas, así como radioterapia concomitante. El paciente presentó estomatitis grado 3, pérdida de peso del $17 \%$ y deterioro de sus condiciones generales con nivel funcional de Karnofsky (KS) de $50 \%$, por lo que se suspendió el tratamiento. Solo recibió un ciclo de quimioterapia y radioterapia (10 Gys). Finalmente, presentó náuseas, vómitos y disfagia, con deterioro progresivo hasta que falleció cinco meses después de su ingreso, con datos de actividad tumoral intra-abdominal.

\section{Caso 2}

Hombre de 39 años con antecedente de abuela y tía paternas fallecidas por cáncer gástrico. Historia de tabaquismo y alcoholismo ocasional desde los 20 años de edad. Cursó con cuadro de melena de 4 meses de evolución y posteriormente, astenia.
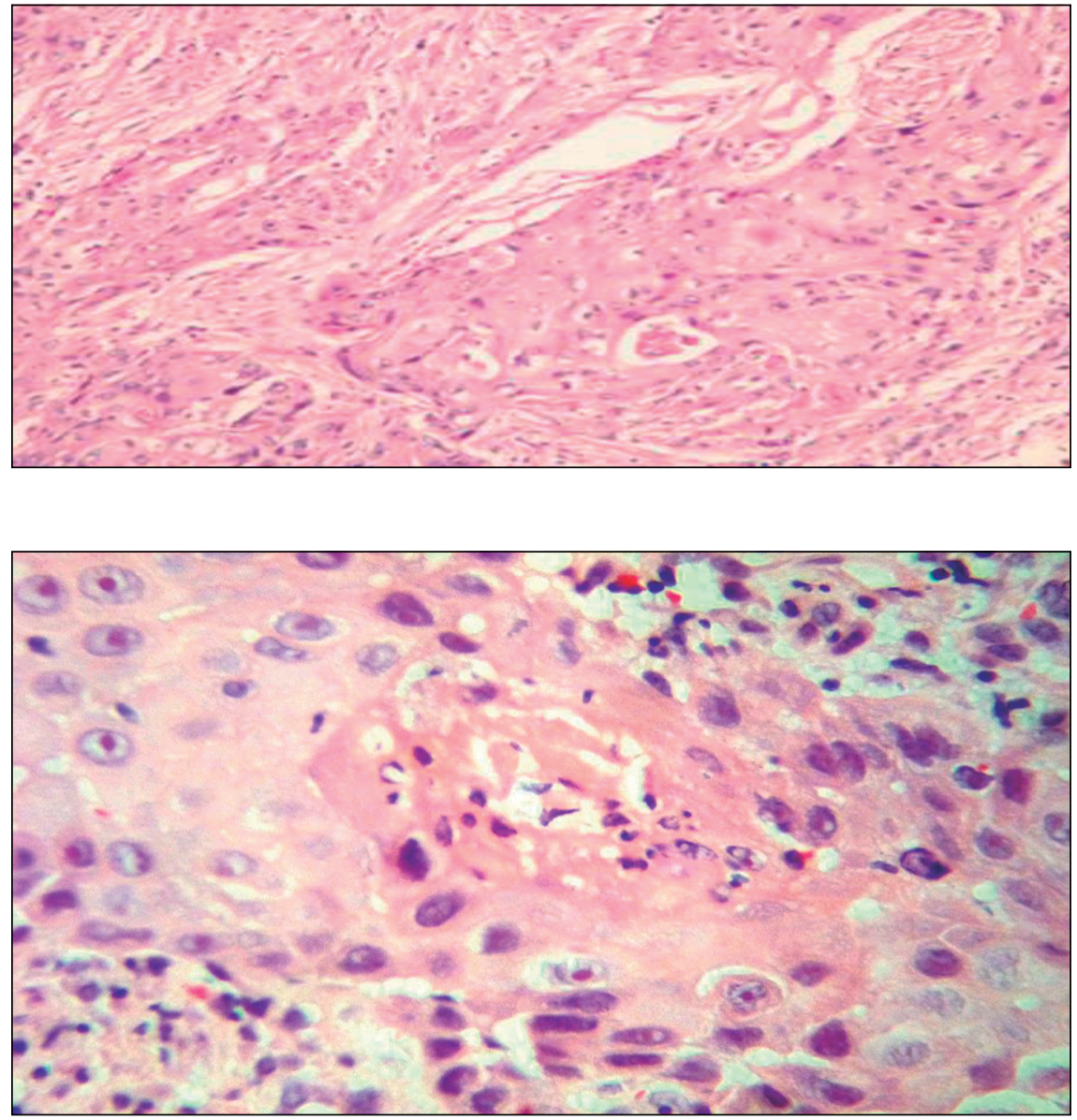

Figura 1. Se observan láminas de células neoplásicas que infiltran la capa muscular propia (H\&E; 10X).
Figura 2. Las células neoplásicas muestran citoplasma eosinófilo amplio, bordes citoplásmicos bien definidos, núcleos ovales y nucléolo eosinófilo evidente. Hay además, puentes intercelulares y se identifica de queratinización central. (Hematoxilina y eosina, 40X). 
En su consulta médica inicial presentaba palidez de tegumentos, $\mathrm{KS} 90 \%$, Hb 12,9 g/dl, trombocitosis, elevación de transaminasas (ALT $88 \mathrm{UI} / 1$ y AST $148 \mathrm{UI} / \mathrm{l}$ ) y gamaglutamil transpeptidasa (GGT) de 187 UI/l. En la TAC se observó engrosamiento difuso de pared gástrica, mientras que en la endoscopía se identificó un tumor ulcerado en el antro gástrico que histológicamente correspondió a un carcinoma epidermoide. Se efectuó exploración quirúrgica y se confirmó la presencia de un tumor en el antro gástrico, que obstruía 90\% de la luz. Se practicó gastrectomía subtotal. El informe histopatológico fue carcinoma mucoepidermoide de grado alto, con infiltración de la pared gástrica y duodenal, permeación linfática extensa y metástasis en 4/14 ganglios linfáticos regionales disecados. La etapificación final fue pT3, pN1, pM0 (IIIA).

El paciente recibió un ciclo de 5-Fluorouracilo $(5 \mathrm{FU})\left(425 \mathrm{mg} / \mathrm{m}^{2} /\right.$ día $)$ y ácido folínico (AF) $\left(20 \mathrm{mg} / \mathrm{m}^{2} /\right.$ día) por 5 días (abril de 2003$)$, pero presentó toxicidad hepática grado 3 (elevación de GGT, fosfatasa alcalina y transaminasas). Se decidió continuar el tratamiento adyuvante solo con radioterapia, de la que recibió una dosis total de 45,6 Gys. Seis meses después de terminar el tratamiento, el paciente presentó dolor abdominal, pérdida de peso $(6 \mathrm{~kg})$, astenia, náuseas y disfonía. Se documentó en el paciente recurrencia tumoral intra-abdominal y mediastinal. No fue candidato a tratamiento oncológico posterior, falleciendo un año después de su ingreso al INCan.

\section{Caso 3}

Mujer de 79 años de edad, sin antecedentes relevantes. Acudió por primera vez a nuestra institución con historia de dos meses de evolución de astenia, melena, pérdida de peso $(8 \mathrm{~kg})$, náuseas y un cuadro de síncope. En la exploración física se encontró palidez de tegumentos moderada, KS $50 \%$, adelgazada, con tumor palpable en epigastrio y edema de extremidades inferiores. La TAC mostró un tumor de $6 \mathrm{~cm}$, en la porción prepilórica, con afección de la primera porción del duodeno y probable infiltración del hígado por contigüidad. La endoscopía presentó evidencia de un tumor ulcerado, de $5 \mathrm{~cm}$ de diámetro, mayor en la porción distal del antro que infiltraba hasta el píloro. El diagnóstico histológico fue de carcinoma epidermoide poco diferenciado de estómago.
Debido a sus malas condiciones clínicas, recibió tratamiento de mejor soporte médico. Posteriormente, presentó infección urinaria, reacción leucemoide por sepsis y coagulación intravascular diseminada que condicionaron su fallecimiento, en menos de 2 meses de la evaluación inicial en el INCan.

\section{Discusión}

El CEG es una neoplasia rara y la incidencia ha sido informada entre 0,04 y $0,7 \%{ }^{5,8}$, frecuente en hombres mayores de 60 años, con una relación de $3: 1^{9,10}$. En el Instituto Nacional de Cancerología, México (septiembre de 1998-febrero de 2017) se han encontrado solo 3 casos de CEG (0,3\%), de los cuales 2 fueron hombres mayores de 60 años.

No se conoce si los antecedentes familiares de cáncer gástrico pudieran influir en el desarrollo del CEG, pero $2 / 3$ casos presentados tenían familiares con cáncer gástrico. Histología presente con mayor frecuencia en el tercio proximal del estómago, aunque pueden ocurrir en cualquier sitio del estómago, como ocurrió en los tres casos presentados, donde la localización principal fue el antro (2) y el cuerpo gástrico (1). La mayoría de los pacientes presentan síntomas ulcerosos de varios meses e incluso, de varios años de evolución. Los presentes casos, mostraron tiempo de evolución relativamente corto (2-6 meses), con síntomas en común: melena, astenia y pérdida de peso. El cuadro clínico no es característico, es indistinto considerando los casos de adenocarcinoma.

Parks y colaboradores ${ }^{11}$ propusieron los criterios para el diagnóstico: 1) Localización externa al cardias y esófago; 2) Ausencia de carcinoma epidermoide en otro órgano. Boswell y Helwig ${ }^{4}$ establecieron los criterios para confirmar el diagnóstico histológico; de acuerdo a estos criterios se realizó y confirmó el diagnóstico histopatológico en los 3 casos presentados.

La patogénesis del CEG es desconocida, aunque se han propuesto diversas teorías para explicar su origen ${ }^{12-14}$, lo que más se conoce es aquello relacionado con el daño crónico de la mucosa gástrica por ácidos corrosivos, linitis plástica, sífilis congénita o ingesta prolongada de ciclofosfamida, que pudiera predisponer la aparición de metaplasia epidermoide ${ }^{15-16}$. En ninguno de los casos se identificaron cambios en la mucosa.

El tratamiento es similar al adenocarcinoma 
gástrico. En casos con etapa clínica temprana se deberá realizar resección quirúrgica. En la actualidad, en los casos con etapas II a IV resecables, lo aconsejable es dar tratamiento neoadyuvante con quimioterapia y posteriormente cirugía, aunque el abordaje quirúrgico inicial se sigue realizando en muchos centros oncológicos.

Dos pacientes, recibieron tratamiento quirúrgico inicial, aún con evidencia de etapas avanzadas (IIIA y IV, respectivamente) e intento de tratamiento adyuvante con quimioterapia y radioterapia, que no fue posible completar. Los tres pacientes fallecieron rápidamente por actividad tumoral.

En un informe de 51 casos con CEG, donde la mayoría de los pacientes tenían enfermedad localmente avanzada o metastásica, se reitera que el manejo inicial con quimioterapia ${ }^{10}$, el cual deberá considerarse como la mejor opción. No hay un esquema de quimioterapia recomendado, pero en la mayoría de los casos se ha incluido el cisplatino, fluorouracilo, etopósido, mitomicina $\mathrm{Co}$ antraciclinas. En dos pacientes utilizamos $5 \mathrm{Fu}$ \pm cisplatino.

El pronóstico en general es malo a corto plazo, con una supervivencia global a 5 años menor del $10 \%{ }^{6}$, aunque en pacientes japoneses aumenta al $35 \%{ }^{10}$. De los tres pacientes presentados, ninguno sobrevivió más de 1 año posterior al diagnóstico.

\section{Conclusión}

La patogénesis del carcinoma epidermoide permanece incierta. Para el tratamiento oncológico del CEG deben aplicarse las pautas que se siguen en el adenocarcinoma gástrico, en donde la resección quirúrgica primaria es el tratamiento más importante en el caso de las etapas tempranas. Pero considerando que la mayoría de los pacientes se diagnostican en etapas avanzadas, el uso de quimioterapia y/o radioterapia debe ser considerado como el tratamiento primario. El esquema de quimioterapia más utilizado es con cisplatino y 5 -fluorouracilo, aunque combinaciones nuevas que incluyeran taxanos, fluoropirimidonas orales, oxaliplatino o irinotecan podrían utilizarse.

\section{Referencias}

1. Jemal A, Siegel R, Ward E, Hao Y, Xu J, Murray T, et al. Cancer statistics, 2008. CA Cancer J Clin 2008; 58: 71-96.
2. Sarbia M, Becker KF, Höfler H. Pathology of upper gastrointestinal malignancies. Semin Oncol 2004; 31: 465-75.

3. Rolleston HD, Trevor RS. A case of columnar-celled carcinoma of the stomach showing squamous-celled metaplasia. J Pathol Bacteriol 1905; 10: 418-22.

4. Boswell JT, Helwig EB. Squamous cell carcinoma and adenoacanthoma of the stomach. A clinico pathologic study. Cancer 1965; 18: 181-92.

5. Straus R, Heschel S, Fortmann DJ. Primary adenosquamous carcinoma of the stomach. A case report and review. Cancer 1969; 24: 985-95.

6. Volpe CM, Hameer HR, Masetti P, Pell M, Shaposhnikow YD, Doerr RJ. Squamous cell carcinoma of the stomach. Am Surg 1995; 61: 1076-8.

7. Mori M, Iwashita A, Enjoji M. Adenosquamous carcinoma of the stomach: a clinicopathologic analysis of 28 cases. Cancer 1986; 57: 333-9.

8. Schmidt C, Schmidt A, Lüttges JE, Kremer B, Henner-Bruns D. Squamous cell carcinoma of the stomach. Report of a case and review of literature. Hepatogastroenterology 2001; 8: 1033-6.

9. Muto M, Hasebe T, Muro K, Boku N, Othsu A, Fujii T, et al. Primary squamous cell carcinoma of the stomach: a case report with a review of Japanese and Western literature. Hepatogastroenterology 1999; 46: 3015-8.

10. Okino H, Shinagawa Y, Hiroyoshi M, Shimada K, Watanabe J, Takeda Sh. A Case of primary squamous cell carcinoma of the stomach: a review of 51 cases in Japanese literature. Jpn J Gastroenterol Surg 2006; 39: 1803-10.

11. Parks RE. Squamous neoplasms of the stomach. Am J Roentgenol Radium Ther Nucl Med 1967; 101: 447-9.

12. Mori M, Fukuda T, Enjoiji M. Adenosquamous carcinoma of the stomach: histogenesis and ultrastructural studies. Gastroenterology 1987; 92: 1078-82.

13. Adachi Y. Squamous cell carcinoma of the stomach. Gastric Cancer 1999; 2: 244-5 (letter to the editor).

14. Callery CD, Sanders MM, Pratt S, Turnbull AD. Squamous cell carcinoma of the stomach: a study of four patients with comments on histogenesis. J Surg Oncol 1985; 29: 166-72.

15. McLoughlin GA, Cave-Bigley DJ, Tagore V, Kirkham N. Cyclophosphamide and pure squamous cell carcinoma of the stomach. Br Med J 1980; 280: 524-5.

16. Eaton H, Tennekoon GE. Squamous carcinoma of the stomach following corrosive acid burns. Br J Surg 1972; 59: 382-7.

17. Jeon MS, Kim GH, Park DY, Jeong JH, Kahng DH, Jang HY, et al. A case of squamous metaplasia of the stomach. Clinical endoscopy 2013; 46 (4): 407. 
18. Rojas PG, Parikh J, Vishnubhotla P, Oharriz JJ. Primary gastric squamous cell carcinoma. Cureus 2018; 10 (3): e2389.

19. Wakabayashi H, Matsutani T, Fujita I, Kanazawa Y, Nomura T, Hagiwara N, et al. A rare case of primary squamous cell carcinoma of the stomach and a review of the 56 cases reported in Japan. J Gastric Cancer 2014; 14 (1): 58-62.

20. Chen Y, Zhu H, Xu F, Cao Y, Gu X, Wan Y, et al. Clinicopathological characteristics, treatment and prognosis of 21 patients with primary gastric squamous cell car- cinoma. Gastroenterol Res Pract 2016; 2016: 3062547. $10.1155 / 2016 / 3062547$.

21. Meng Y, Zhang J, Wang H, Zhang Y, Sun R, Zhang Z, et al. Poorer prognosis in patients with advanced gastric squamous cell carcinoma compared with adenocarcinoma of the stomach: case report. Medicine (Baltimore). 2017; 96: e9224. 10.1097/MD.0000000000009224.

22. von Waagner W, Wang Z, Picon AI. A rare case of a primary squamous cell carcinoma of the stomach presenting as a submucosal mass. Case Reports in Surgery 2015, Article ID 482342, 5 pages, 2015. 